Bulbrook, R. D., Greenwood, F. C., and Hayward, J. L. (1960). Lancet, 1,1154 .

Bulbrook, R. D., Hayward, J. L., Spicer, C. C., and Thomas, B. S. (1962). Lancet, 2, 1238 .

Cameron, E. H. D. (1969). The Human Adrenal Gland and its Relation to Breast Cancer, ed. K. Griffiths, and E. H. D. Cameron, p. 47. Cardiff, Alpha Omega Alpha.

Hayward, J. L., and Bulbrook, R. D. (1968). Prognostic Factors in Breast Cancer, ed. A. P. M. Forrest, and P. B. Kunkler, p. 383. Edinburgh,
Livingstone.
Metcalfe, M. G. (1963). Fournal of Endocrinology, 26, 415.

Miller, H., Durant, J. A., Jacobs, A. G., and Allison, J. F. (1967). British Medical fournal, $1,147$.

Miller, H., and Durant, J. A. (1968). Clinical Biochemistry, 1, 286.

Miller, H., and Durant, J. A. (1969). Lancet, 1, 1313.

Nabarro, J. D. N. (1960). Lancet, 1, 1293.

Rao, I G. S (1970). Lancet, 2 , 141 .

Thomas, B. S., Bulbrook, R. D, and Hayward, J. L (1967). British Medical fournal, 2, 523.

Thomas, B. S., Bulbrook, R. D., Durant, J. A., Miller, H., and Ross, D. M. (1969). Clinical Biochemistry, 2, 311.

\title{
Malignant Carcinoid Tumour with Gangrene of the Small Intestine
}

\author{
IAIN M. MURRAY-LYON, M. O. RAKE, A. K. MARSHALL, ROGER WILLIAMS
}

British Medical fournal, 1973, 4, 770-771

\begin{abstract}
Summary
Four patients with a malignant carcinoid tumour of the small bowel (three had the carcinoid syndrome) developed gangrene of the small intestine. Attention is drawn to this seldom recognized complication, as early surgery may be life saving.
\end{abstract}

\section{Introduction}

Abdominal pain commonly occurs in the carcinoid syndrome and is usually secondary to the disturbance of intestinal motility. Intestinal obstruction either due to the tumour itself or to kinking of the bowel caused by the commonly associated fibrous reaction may also occur (McNeal, 1971; GrahamSmith, 1972). Yet another cause of abdominal pain, but one not well known, is gangrene of the small intestine. In this paper we report on four patients in whom we have seen this develop. Recognition is vital since a fatal outcome is inevitable unless early surgery is carried out.

\section{Case Histories}

Case 1.-This 70-year-old man started to have severe episodes of flushing and diarrhoea in February 1969. Urinary 5-hydroxyindole acetic acid (5-HIAA) excretion was raised $(54-70 \mathrm{mg} / 24 \mathrm{hr}$ ) as was the blood 5-hydroxytryptamine $(5-\mathrm{HT}$ ) at $0.83 \mu \mathrm{g} / \mathrm{ml}$ (normal $0.037-0.28 \mu \mathrm{g} / \mathrm{ml}$ ). Liver biopsy showed metastatic carcinoid tissue. The primary site appeared to be a stenosing lesion in the mid ileum. The latter was bypassed by a side-to-side anastomosis, the hepatic metastases being treated by local perfusion of fluorouracil followed by ligation of the hepatic artery (case 6, MurrayLyon et al., 1970). For a year he was much improved but then the diarrhoea and flushing again became troublesome, the urinary 5-HIAA excretion having increased again to preoperative levels. In June 1970 he was readmitted to hospital with bronchopneumonia but then developed abdominal pain with signs of peritonitis and he died three days later. At necropsy (Dr. I. M. Magrath) there was a

\footnotetext{
Liver Unit and Department of Morbid Anatomy, King's College Hospital, London SE5 8RX, and Guy's Hospital, London SE1 9RT IAIN M. MURRAY-LYON, M.B., M.R.C.P., Senior Registrar in General Medicine

M. O. RAKE, M.B., M.R.C.P., Research Fellow (Present appointment: Consultant Physician, Kent and Canterbury Hospital, Canterbury) A. K. MARSHALL, M.B., M.R.C.PATH., Senior Registrar ROGER WILLIAMS, M.D., F.R.C.P., Physician, and Director of Liver Unit
}

mass of carcinoid tumour in the mid jejunum and the adjoining mesentery incorporating several large lymph nodes. Through this passed a branch of the superior mesenteric artery supplying a $1-m$ length of mid-ileum which had become gangrenous. Histological examination of the part of the artery passing through the tumour mass showed dense elastic tissue in both the intima and adventitia (see photograph). The lumen appeared narrowed but no thrombus was present. Similar changes were present in the accompanying vein.

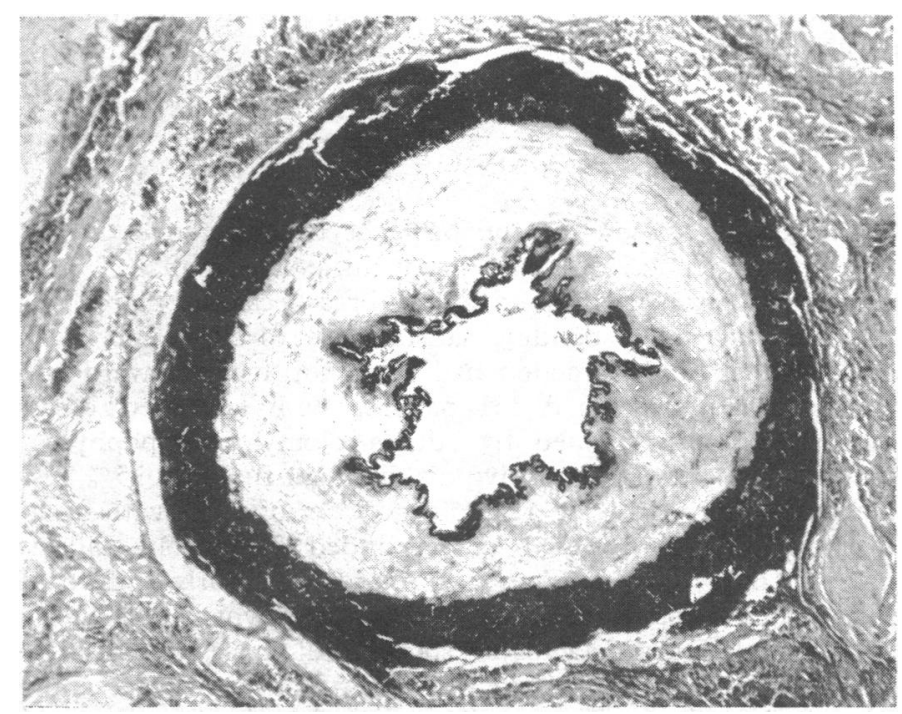

Mesenteric artery from case 1 showing elastic sclerosis of the adventitia. (Elastic van Gieson. x 30.)

Case 2.-A 38-year-old woman was found to have a carcino:d tumour of the terminal ileum with multiple hepatic and peritoneal metastases in January 1969. A bypass operation was performed and she remained reasonably well over the next two years, though increasingly troubled by attacks of flushing and diarrho:a. When investigated again in October 1971 she had gross hepatomegaly, and both urinary 5-HIAA $(240-550 \mathrm{mg} / 24 \mathrm{hr})$ and blood 5-HT $(1.88 \mu \mathrm{g} / 100)$ were greatly raised. Some control of her symptoms was achieved by codeine phosphate, but after a few weeks she was readmitted with a five-day history of increasing abdominal pain and diarrhoea. Examination showed generalized abdominal tenderness, and a few days later signs of peritonism appeared and plain films of the abdomen showed signs of small bowel obstruction. Peritoneal tap produced faeculent fluid. Her general condition deteriorated rapidly and she died six days after admission. At necropsy there was purulent peritonitis. Loops of ileum were 
matted together and several were gangrenous. There were numerous secondary deposits in the liver and peritoneal cavity, par ticularly in the mesentery. Histological examination of the mesenteric vessels showed proliferation of the elastic tissue in the adventitia, and in one of these the lumen was occluded by what appeared to be organized thrombus.

Case 3.- This 67-year-old woman was found to have secondary deposits in both lobes of the liver in July 1970 at the time of a gastric antrectomy for a benign adenomatous polyp. Over the $n$ ? 18 months she had recurrent bouts of abdominal pain and diarrhoea with loss of $12 \mathrm{~kg}$ in weight. In January 1972 she was readmitted for investigation. Urinary 5-HIAA excretion was normal, but while in the ward her abdominal pain became more severe and persistent. Over a period of four days she developed abdominal distention with rebound tenderness, and plain films of the abdomen showed distension of the small bowel. Laparatomy (Mr. H. Berry) showed purulent peritonitis with gangrene of the lower jejunum and ileum and pronounced venous congestion of the rest of the small bowel. There was a mass of tumour tissue in the root of the mesentery. No operative procedure was possible and she died a few hours later. At necropsy (Dr. K. B. Shilkin) there was a plaque of carcinoid tissue in the wall of the necrotic ileum and the root of the mesentery was invaded with tumour. One vessel contained recent thrombus, and histological examination of the vessels showed striking reduplication of elastic tissue in both the adventitia and intima. One vessel showed fine intimal fibros:s due possibly to recanalization of an old thrombus.

Case 4.- This 56-year-old man had first noted flushing attacks in 1967 and since 1969 had had attacks of central abdominal pain lasting several days at a time. In April 1972 he was admitted to hosital because of increasingly troublesome symptoms. Urinary 5-HIAA excretion was appreciably raised $(92 \mathrm{mg} / 24 \mathrm{hr}$ ). Laparotomy showed numerous small hepatic mestatases, with a primary tumour in the terminal ileum extending into the mesentery. This was bypassed with an enteroanastomosis. Subsequently he was treated with repeated courses of fluorouracil and mitomycin C and methysergide, but with little improvement. In January 1973 he was readmitted with a two-day history of lower abdominal pain and tenderness. After three days signs of peritonitis developed. At laparatomy (Mr. R. Lawrie) a 40-cm section of gangrenous small intestine was found which had perforated in two places. This was resected together with a mass of tumour tissue and fibrous tissue in the root of the mesentery. The patient died some weeks later from septicaemia. Histological examination of the resected specimen showed infarcted small intestine containing a classical ileal carcinoid tumour which extended into the root of the mesenterv. There it was embedded in dense fibrous tissue containing elastic deposits. Elastic sclerotic change were present in the adventitia of the mesenteric vessels.

\section{Discussion}

There are sporadic references in the literature to gangrene of the small intestine in association with a carcinoid tumour. Some, like three of our cases, had clinical or biochemical evidence of excess 5-hydnoxyindole secretion (Kowlessar et al.,
1959; Moertel et al., 1961; Nash and Brin, 1964; Anthony, 1970) but in other cases the tumour appears to have been funotionless (Anthony, 1970; Jouanneau et al., 1970). The development of gangrene of the small intestine may be difficult to recognize and distinguish from the other causes of abdominal pain associated with carcinoid tumours mentioned above, but the prolonged and constant quality of the pain may be of diagnostic help. We were struck by the insidious presentation in three of our cases, and though the patients were under constant hospital supervision it was several days before it was apparent that peritonitis had developed. Though all of our patients died recognition of this complication should lead to earlier laparotomy with the chance of reseoting the affected segment of bowel. The cases reponted by Kowlessar et al., (1959) and Nash and Brin (1964) were successfully treated.

The cause of the ischaemic change is seldom clear, though in a few cases there is an obvious mechanical basis such as volvulus of the small intestine (Horsley and Baker, 1970). Anthony and Drury (1970) drew attention to the characteristic proliferation of elastic tissue in the adventitia and intima of the mesenteric vessel. This was a prominent feature in all our cases, but the vessel lumens were not much narrowed, and this alone does not seem sufficient to account for the development of gangrene. In two of our cases thrombosis of mesenteric vessels had probably also occurred and this, together with restriction of mesenteric flow due to pressure by tumour tissue and the striking fibrous reaction in the root of the mesentery, is likely to be more important. The pathogenesis of the characteristic fibrous reaction is unknown (Sandler, 1968).

We are grateful to Dr. T. M. L. Price and Mr. J. E. H. Pendower for referring the first two cases, and to $\mathrm{Dr}$. C. Joiner for allowing us to include case 4. Dr. M. O. Shelton and Dr. K. Missen provided pathological material and Dr. Merton Sandler performed the blcod 5-hydroxytryptamine estimations.

\section{References}

Anthony, P. P. (1970). British Fournal of Surgery, 57, 118. Anthony, P. P., and Drury, R. A. B. (1970). fournal of Clinical Fathology,

Graham-Smith, D. G. (1972). The Carcinoid Syndrome, p. 56. London, Heinemann.

Horsley, B. L., and Baker, R. R. (1970). American Surgeon, 37, 676.

Jouanneau, P., Malafosse, M., Boureille, J., and Hemet, J. (1970). Chirugie, 96,756

Kowlessar, O. D., Law, D. H., and Sleisenger, M. H. (1959). American fournal of Medicine, 27, 673 .

McNeal, J. E. (1971). American fournal of Clinical Pathology, 56, 452.

Moertel, C. G., Sauer, W. B., Dockerty, M. B., and Baggenstoss, A. H (1961). Cancer, 14, 901.

Murray-Lyon, I. M., et al. (1970). Lancet, 2, 172

Nash, D. T., and Brin, M. (1964). New York State fournal of Medicine, 64, 1128

Sandler, M. (1968). In Advances in Pharmacology, ed. S. Garattini and P. A. Shore, vol. 6, part B, p. 127. New York, Academic Press. 